\title{
COVID-19 and Type 1 diabetes in Sweden
}

\author{
Johnny Ludvigsson \\ Crown Princess Victoria Children's Hospital and Div of Pediatrics, Linköping university, Sweden
}

${ }^{\star}$ Corresponding author: Johnny Ludvigsson, Crown Princess Victoria Children's Hospital and Div of Pediatrics, Dept of Biomedical and Clinical Sciences, Linköping university, Linköping, Sweden

Received: May 04, 2020; Accepted: May 14, 2020; Published: June 06, 2020

\begin{abstract}
COVID19 is regarded as a lifethreatening infection for most people, but especially certain risk-groups including diabetes, and has therefore caused lockdown of societies which may have deleterious consequences. Many countries have taken steps to shut down schools, companies and businesses, and entire countries have been isolated. These drastic measures will have serious consequences for economy, psychosocial situation and health. There is a risk that people with other diseases like diabetes do not get ordinary adequate care.

Sweden has as the only country chosen another policy with recommended isolation of the most vulnerable populations, mainly people older than 70 years of age, and volontary isolation of others who have eg serious lung disease och extreme obesity. For everybody physical distancing, increased hygiene, at home when symptoms of COVID19, crowds $<50$ people etc Otherwise open shops, open restaurants, open schools.

In the care of children and adolscents with Type 1 diabetes has some ordinary visits to the diabetesteam been replaced by telemedicine. Quality has remained the same as 2018 and 2019 with national mean HbA1c $53.8 \mathrm{mmol} / \mathrm{mol}$ ( 95\% CI 53-5- 54.1) during Jan 1- April 28, 2020 and the proportion of patients with $\mathrm{HbA} 1 \mathrm{c}<57 \mathrm{mmol} / \mathrm{l}$ was $67.3 \%$ ( 95\% CI 66-68.6\%). Type 1 diabetes has not been a risk factor for severe COVID19, and no children with T1D are among those who have needed Intensive Care or who have died.
\end{abstract}

Keywords: COVID19, public health, economic depression, vulnerable groups, isolation

Severe Acute Respiratory Syndrome Coronavirus-2 (SARSCoV-2), the virus that causes coronavirus disease 2019 (COVID-19), is a major threat. Many countries have taken steps to shut down schools, companies and businesses, and entire countries have been isolated. These drastic measures will have serious consequences for economy, psychosocial situation and health.

Sweden has as the only country chosen another policy with recommended isolation of the most vulnerable populations, mainly people older than 70 years of age, and volontary isolation of others who have eg serious lung disease och extreme obesity. Otherwise open shops, open restaurants, open nursery and primary schools. In spite of this open policy and a high rate of infected people fatality rate has remained in the middle range of European countries.

Diabetes is regarded as one of the risk factors for COVID19 [1-4]. This seems especially true for Type 2 diabetes connected to metabolic syndrome with hypertension, cardio-vasculare disease, and obesity. According to Yang et al., among 52 critically ill patients, diabetes was present in $17 \%$ of cases [5]. According to Guan et al., among 1099 patients, diabetes was present in $16.2 \%$ of cases and hypertension was present in $23.7 \%$ of cases [6] and according to Zhang et al., among 140 hospitalized patients, diabetes was present in $12 \%$ of cases and hypertension was present in $30 \%$ of cases [7]. In children $<18$ years of age, COVID19 is usually a mild disease, which very seldom leads to any dangerous clinical manistestation [8]. For children with Type 1 diabetes ( T1D) the large scale lock-down of society might have very negative impacts. There is a risk that patients who get symptoms of diabetes do not dare to seek care which could lead to more severe clinical manifestation at onset. Another risk of severe lock-down of society is that patients with diabetes do not get ordinary adequate care.

The aim of this study was to get a picture of the need for care at Intensive Care Unit in Sweden until now (April 28 ${ }^{\text {th }} 2020$ ), the proportion of patients with diabetes and need for ICU in children and adolescents. In addition the aim was to investigate how quality of care of children and adolescents with T1D in Sweden has been influenced by the ongoing pandemic.

\section{Material and Methods}

Sweden has next to Finland the highest incidence of T1D in children and adolescents in the world [9]. All patient visits are registered in a national data base, SWEDIABKIDS [10] with information about $\mathrm{HbAlc}$, blood lipids etc. In what way the coronavirus epidemic has influenced care is described after regular contacts between diabetesteams at pediatric clinics. All patients needing intensive care are registered in the Swedish Register for Intensive Care, in which also all patients needing ICU because of COVID19 are registered [11].

\section{Results}

Some diabetes clinics have continued in the same way as before. Patients have come to the hospital for ordinary visits and met members of the diabetesteams. Other diabetes teams have during the corona epidemic started to use telemedicine as a complement, meaning that patients, and for children their parents, have been contacted via telephone and/or skype, and in addition blood glucose values have been uploaded from glucose sensors and evaluated using 
Diasend. National HbA1c has remained stable: For children $<18$ years of age mean $\mathrm{HbAlc}$ for all Sweden was $201854.7 \mathrm{mmol} / \mathrm{mol}$ (95\% confidence interval 54.4-55), for 201953.3 ( 53-53.6) and for 2020 ( jan 1- April 28) 53.8 ( 53-5- 54.1). The proportion of patients with $\mathrm{HbAlc}<57 \mathrm{mmol} / \mathrm{l}$ was $201863.4 \%$ ( 95\% confidence interval 62.3-64.5\%), $201968.3 \%$ (67.2-69.4\%) and for 2020 ( Jan 1- April 28) $67.3 \%$ ( 66-68.6\%). Kolesterol values are registered between age 10-18 years and proportion < 4.5 was 2018 69\% ( 66.7- 71.3), $201969.9 \%$ ( 67.5-72.3) and 2020 so far $71.6 \%$ (68.4- 74.8). Looking at any other parameter in the quality register shows the same trend: No difference between 2020 so far (April 28 ${ }^{\text {th }}$ ) and the previous two years.

Regarding severity of COVID19 and the result of the Swedish approach in comparison with the lock-down of other European countries it is difficult to draw conclusions as the different countries have different degree proportions of infected population. Sweden , with its rather open society has already a high proportion of infected people in the general population, with certain areas having passed $25 \%$ of the population, while some countries calculate with much lower proportions. Number of deaths in Sweden are shown in Figure 1. Mean age of dead people was 81 years. A large majority (93\%) of the dead persons belonged to at least one risk group, with chronic cardiovascular disease being the most prevalent, followed by diabetes, chronic respiratory disease and chronic renal failure (Table 1). Number of patients at Intensive Care Unit (ICU) is shown in Figure 2 which illustrates that the numbers per day is kept rather stable. Fig 3 shows that males dominate and that there are almost no young individuals needing ICU except for rare cases with severe other underlying diseases, not Type 1 diabetes.

\section{Discussion}

The Corona virus pandemic threathens ordinary health care, Many countries have become paralysed and there is a risk that treatment of serious diseases like Type 1 diabetes in children and adolescents deteriorate, which may take long time to repair. With poor metabolic control we know that there is an increasing risk of vaculsar complications, and $\mathrm{HbAlc}$ has to be kept quite low to avoid long-term vascular complications [12-14]. Sweden has a tradition of very active treatment of T1D with low mean HbA1c on a national level compared to many other countries [15]. In spite of this active treatment those who have got the diagnosis Type 1 diabetes in childhood have a much shorter expected length of life than a reference population [16]. It is therefore mandatory to try to keep quality of care also during the corona pandemic.

When society is closed because of the this pandemic telemedicine is an alternative to ordinary visits to the diabetes team [17]. This may

Table 1. Risk factors for patients who have needed Intensive Care becuase of COVID19 in Sweden until 28th April 2020

\begin{tabular}{|c|c|c|c|c|c|}
\hline Riskgroup & Females (\%) & $(\mathbf{n})$ & Male $\quad(\%)$ & (n) & Number of persons \\
\hline$>65$ years of age & 9,0 & 167 & 26,6 & 495 & 528 \\
\hline Child, several handicap & 0,0 & 0 & 0,0 & 0 & 0 \\
\hline Pregnancy & 1,2 & 22 & 0,0 & 0 & 15 \\
\hline Hypertension & 8,4 & 156 & 28,2 & 524 & 544 \\
\hline Chronic heart-lung disease & 5,6 & 104 & 16,0 & 298 & 340 \\
\hline Chronic heart disease & 1,4 & 26 & 8,8 & 164 & 166 \\
\hline Chronic lung disease & 4,5 & 84 & 8,6 & 159 & 204 \\
\hline Immune deficiency & 1,7 & 31 & 3,0 & 55 & 76 \\
\hline Chronic liver/renal disease & 0,7 & 13 & 2,8 & 52 & 60 \\
\hline Chronic liver insuff & 0,2 & 4 & 0,4 & 7 & 11 \\
\hline Chronic renal insuff & 0,5 & 10 & 2,5 & 46 & 51 \\
\hline Diabetes & 5,4 & 100 & 18,2 & 339 & 349 \\
\hline Extreme obesity & 2,3 & 43 & 3,8 & 71 & 96 \\
\hline Neuromuscular disease & 0,3 & 5 & 0,7 & 13 & 17 \\
\hline Other disease & 2,7 & 50 & 8,0 & 149 & 189 \\
\hline
\end{tabular}

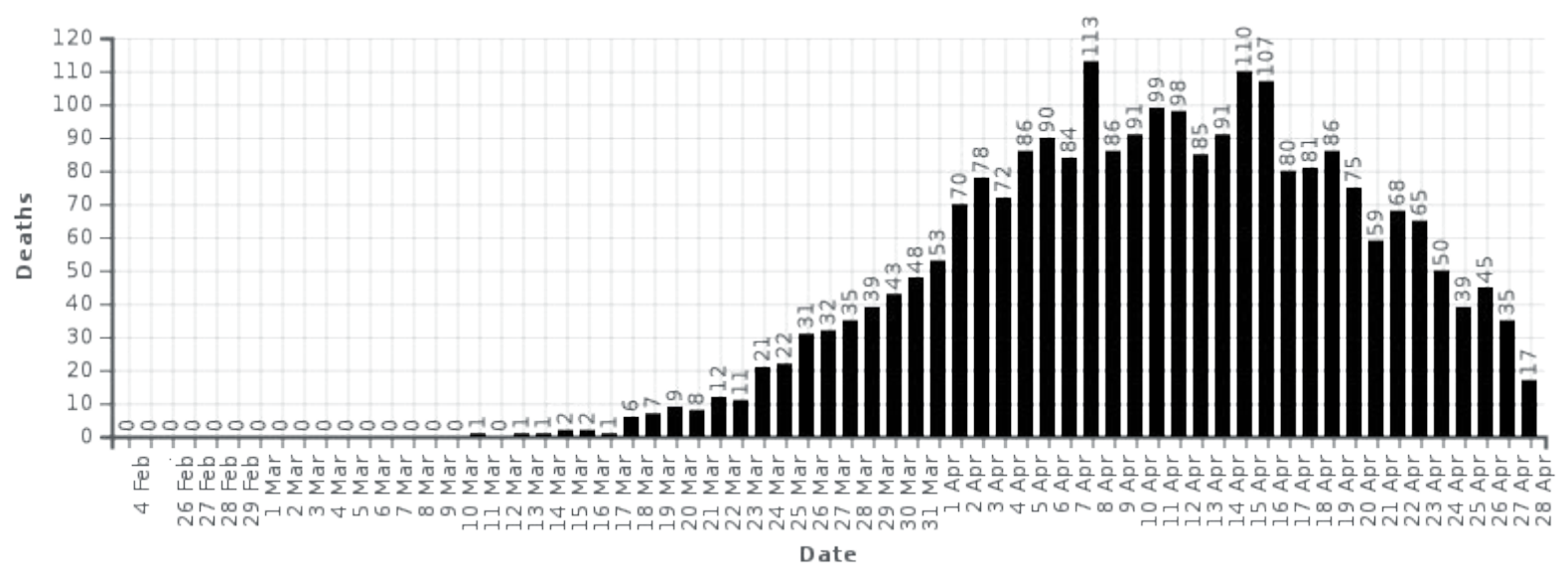

Figure 1. Number of covid19-related deaths per day in Sweden 


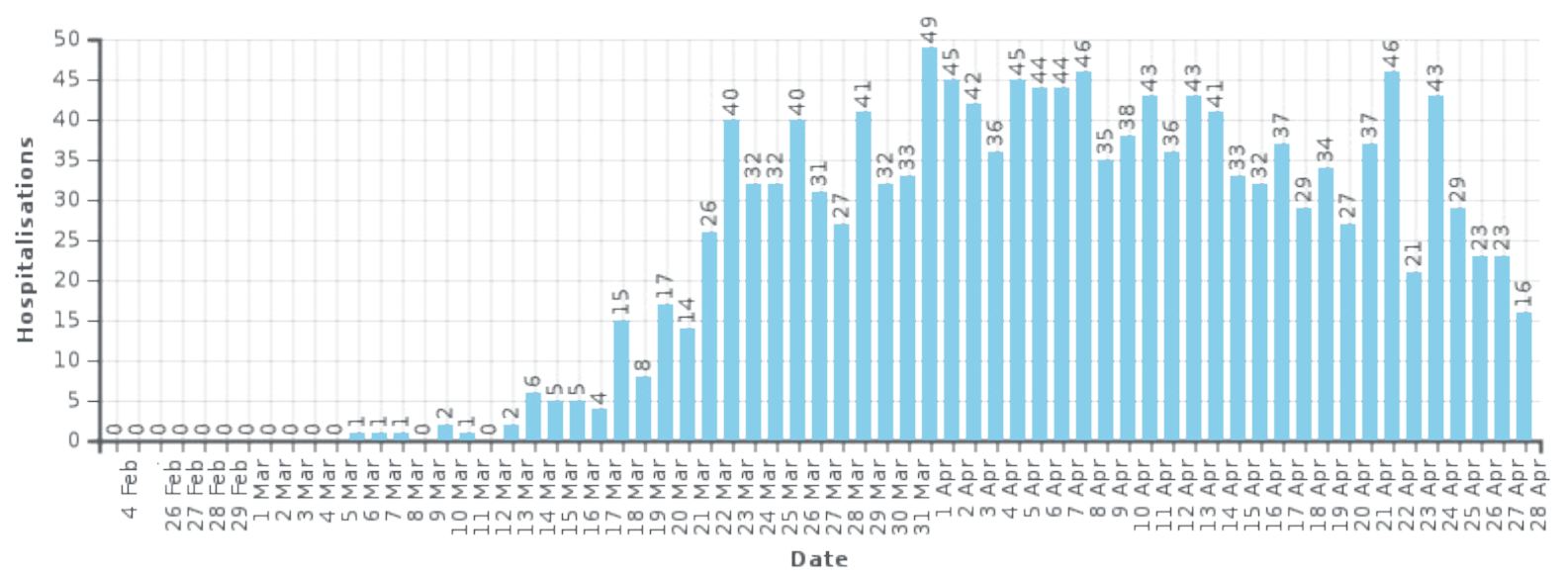

Figure 2. Number of covid19-related deaths per day in Sweden

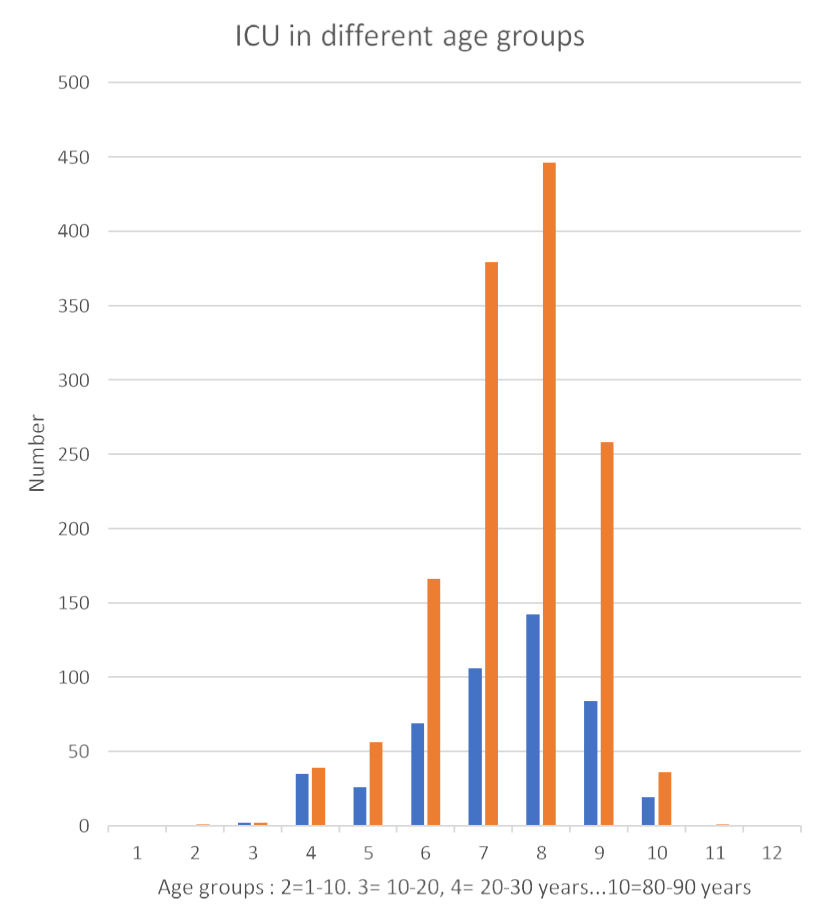

Figure 3. ICU in different age groups. Blue: Females, Orange: Males.

become a valuable experience which in the future might improve care when used as a complement, but there will also be a risk that both diabetes teams and patients/parents continue with this type of contacts instead of physical visits as it seems comfortable. Health care authorities may also become positive to this cheaper form av care. However, digital visits have certain advantages, but do not give the same type of contact as a physical meeting. This could lead to less motivation and deteriorating metabolic control .

During the corona pandemic Sweden has, unlike many other countries, not imposed any lockdown, with most measures being voluntary. The Swedish constitution prohibits ministerial rule and mandates that the relevant government body, in this case an expert agency, the Public Health Agency, must initiate all actions to prevent the virus, rendering the state epidemiologist a central figure in the crisis. The government can follow agency recommendations, as it has with legislation limiting freedom of assembly, temporarily banning gatherings of over 50 individuals, banning people from visiting nursing homes, as well as physically closing secondary schools and universities. Primary schools have remained open, in part to avoid healthcare workers staying home with their children.

The Public Health Agency and government have issued recommendations to: if possible, work from home; avoid unnecessary travel within the country; to engage in physical distancing; and for people above 70 to stay at home, as much as possible. Those with even minimal symptoms that could be caused by COVID-19 are recommended to stay home. The 'karensdag' or initial day without paid sick-leave has been removed by the government and the length of time one can stay home with pay without a doctor's note has been raised from 7 to 21 days. This approach has made it possible to keep the infection rate at such a level that the number of individuals needing intensive care because of COVID19 has remained at a steady state, and all the time there has been a reserve capacity of ca $20 \%$ of ICU beds.

Although a large proportion of the patients at ICU has had diabetes, most of them have had T2D, and no children or even young adults with T1D has needed ICU. T1D has not been regarded as a riskgroup in children and adolescents, and as society has been kept open the care and treatment of T1D has remained of good quality. There is so far no sign of deterioration of metabolic control, with $\mathrm{HbAlc}$ values which remain low compared to what is reported from other contries [15]. Ordinary visits at hospital has sometimes been replaced by virtual meetings with the use of internet. Thus, treatment of children and adolescents with Type 1 diabetes has worked well in spite of some lack of staff in the diabetes teams as some have been ill or stayed at home because of possible COVID19 symptoms, and also because some members of the diabetes teams have been ordered to be part of COVID19 teams.

The result of approach to fight the corona virus pandemic may have to differ between countries. One reason to different approaches in European countries is probably different political culture, where Sweden differs having strong independent expert authorities and a population with confidence in these authorities. Other countries may have more need for "strong" political leaders making their own decisions, not always based on the basis of scientific evidence. The lock- 
down of societies evidently stop or at least delay the spread of corona virus, but only to some extent. The fatality rate has remained lower in some countries than in Sweden, but also much higher in several other European countries with strict lock-down. This lock-down approach is not sustainable for an extended period due to its drastic and increasing economic and social consequences. Furthermore, even if successful, universal curfews would have to be implemented over many months or perhaps longer then so. The economic collapse with mass unemployment would have deterious effects on health including increasing mortality also in younger age groups. As an example the much less severe economic turbulence 2009 was calculated to cause the death of 260000 individuals just by cancer [18] , and the negative effects on health in the developing countries was very large [19]. Another risk is the care of diabetes, as poor metabolic control may lead to long-term serious consequences for a large number of patients, with increased mortaliy many years later. In addition, long lock-down and economic collapse will, over time, destabilize society, not only through tremendous economic losses, but also through the risk of increasing social unrest and the psychological consequences of social isolation [20].

In conclusion, the corona pandemic may have great influence on the the care of Type 1 diabetes, which may have both actual and future effects. Type 1 diabetes is a lifethreatening disease. Too late diagnosis can lead to ketoacidosis and death. Poor metabolic control leads to serious complications and shorter life. The corona virus epidemic tends to paralyse societies and influence health care, which in the long run may ead to more serious effects on morbidity and mortality in young people than the corona virus per se. A more open approach based on isolation of vulnerable groups, mainly the elderly, but otherwise a functioning society is an alternative way to both manage the pandemic and at the same time keep a high standard of diabetes care.

\section{Acknowledgements}

This study has been facilitated by the contacts created by SWEDIABNET ( The Swedish Pediatric Diabetes Trial network) supported by Vinnova and Barndiabetesfonden ( the Swedish Child Diabetes Foundation)

\section{Disclosure}

Johnny Ludvigsson has anything to disclose, and no conflict of interest.

\section{References}

1. Clerkin KJ, Fried JA, Raikhelkar J, et al. Coronavirus Disease 2019 (COVID-19) and Cardiovascular Disease. Circulation 2020.

2. Zhou F, Yu T, Du R, et al. Clinical course and risk factors for mortality of adult inpatients with COVID-19 in Wuhan, China: a retrospective cohort study. The Lancet 2020.

3. Driggin E, Madhavan MV, Bikdeli B, et al. Cardiovascular Considerations for Patients, Health Care Workers, and Health Systems During the Coronavirus Disease 2019 (COVID-19) Pandemic. Journal of the American College of Cardiology 2020: 27204 .
4. [The epidemiological characteristics of an outbreak of 2019 novel coronavirus diseases (COVID-19) in China]. Zhonghua liu xing bing xue za zhi = Zhonghua liuxingbingxue zazhi 2020; 41(2): 145-51.

5. Yang X, Yu Y, Xu J, Shu H, Xia J, Liu H, Wu Y, Zhang L, Yu Z, Fang M, Yu T, Wang Y, Pan S, Zou X, Yuan S. Clinical course and outcomes of critically ill patients with SARS-CoV-2 pneumonia in Wuhan, China: a single-centered, retrospective, observational study. [Published online ahead of print (February 24, 2020)]. Lancet Respir Med. 2020. [PMC free article] [PubMed]

6. Guan WJ, Ni ZY, Hu Y, Liang WH, Ou CQ, He JX, Liu L, Shan H, Lei CL, Hui DS, Du B, Li LJ, eng G, Yuen KY, Chen R, Tang CL, Wang T, Chen PY, Xiang J, Li SY, Wang JL, Liang ZJ, Peng YX, Wei L, Liu Y, Hu YH, Peng P, Wang JM, Liu JY, Chen Z, Li G, Zheng ZJ, Qiu SQ, Luo J, Ye CJ, Zhu SY, Z NS Clinical characteristics of coronavirus disease 2019 in China. [Published online ahead of print (February 28, 2020)]. N Engl J Med. 2020

7. Zhang JJ, Dong X, Cao YY, Yuan YD, Yang YB, Yan YQ, Akdis CA, Gao YD. Clinical characteristics of 140 patients infected with SARS-CoV-2 in Wuhan, China. [Published online ahead of print (February 19, 2020)]. Allergy. 2020. [PubMed]

8. Ludvigsson JF. Systematic review of COVID-19 in children show milder cases and a better prognosis than adults. Acta Paediatrica; 2020 Mar 23. doi: 10.1111/apa.15270

9. Ludvigsson J.Increasing Incidence but Decreasing Awareness of Type 1 Diabetes in Sweden. Diabetes Care. 2017 Oct;40(10):e143-e144. doi: 10.2337/dc17-1175

10. Hanberger L, Samuelsson U, Lindblad B, Ludvigsson J; Swedish Childhood Diabetes Registry SWEDIABKIDS. A1C in children and adolescents with diabetes in relation to certain clinical parameters: the Swedish Childhood Diabetes Registry SWEDIABKIDS. Diabetes Care. 2008 May;31(5):927-9. doi: 10.2337/dc07-1863

11. The Swedish Intensive Care Registry (SIR) https://www.icuregswe.org/

12. Nordwall M, Abrahamsson M, Dhir M, Fredrikson M, Ludvigsson J, Arnqvist HJ.Impact of HbAlc, followed from onset of type 1 diabetes, on the development of severe retinopathy and nephropathy: the VISS Study (Vascular Diabetic Complications in Southeast Sweden). Diabetes Care. 2015 Feb;38(2):308-15. doi: $10.2337 / \mathrm{dc} 14-1203$.

13. Nordwall M, Fredriksson M, Ludvigsson J, Arnqvist HJ. Impact of Age of Onset, Puberty, and Glycemic Control Followed From Diagnosis on Incidence of Retinopathy in Type 1 Diabetes: The VISS Study. Diabetes Care. 2019 Apr;42(4):609616. doi: $10.2337 / \mathrm{dc} 18-1950$

14. Lind M, Pivodic A, Svensson AM, Ólafsdóttir AF, Wedel H, Ludvigsson J. HbA1c level as a risk factor for retinopathy and nephropathy in children and adults with type 1 diabetes: Swedish population based cohort study. BMJ. 2019 Aug 28;366:14894. doi: 10.1136/bmj.14894.

15. Anderzén J, Hermann JM, Samuelsson U, Charalampopoulos D, Svensson J, Skrivarhaug T, Fröhlich-Reiterer E, Maahs DM, Akesson K, Kapellen T, Fritsch M, Birkebaek NH, Drivvoll AK, Miller K, Stephenson T, Hofer SE, Fredheim S, Kummernes SJ, Foster N, Amin R, Hilgard D, Rami-Merhar B, Dahl-Jørgensen K, Clements M, Hanas R, Holl RW, Warner JT. International benchmarking in type 1 diabetes: Large difference in childhood HbAlc between eight high-income countries but similar rise during adolescence-A quality registry study. Pediatr Diabetes. 2020 Apr 6. doi: 10.1111/pedi.13014.

16. Rawshani A, Sattar N, Franzén S, Rawshani A, Hattersley AT, Svensson AM, Eliasson B, Gudbjörnsdottir S. Excess mortality and cardiovascular disease in young adults with type 1 diabetes in relation to age at onset: a nationwide, registerbased cohort study. Lancet. 2018 Aug 11;392(10146):477-486. doi: 10.1016/S01406736(18)31506-X

17. Garg SK, Rodbard D, Hirsch IB, Forlenza GP.Managing New-Onset Type 1 Diabetes During the COVID-19 Pandemic: Challenges and Opportunities. Diabetes Technol Ther. 2020 Apr 17. doi: 10.1089/dia.2020.0161.

18. Maruthappu M, Watkins J, Noor A M, et al. Economic downturns, universal health coverage, and cancer mortality in high-income and middle-income countries, 19902010: a longitudinal analysis. Lancet 2016;388(10045):684-695.

19. Friedman J, Schady N. How many infants likely died in Africa as a result of the 20082009 global financial crisis? Health Economics 2013;22(5):611-622.

20. Armitage R, Nellums LB. COVID-19 and the consequences of isolating the elderly. The Lancet Public Health. 2020 Mar 19. pii: S2468-2667(20)30061-X. doi: 10.1016/ S2468-2667(20)30061 